\title{
O Grupo Bilbao como modelo de transculturalidade e identidade híbrida
}

\author{
The Bilbao Group as a Model of Transculturalism and \\ Hybrid Identity
}

\author{
Begoña Regueiro Salgado \\ Universidad Complutense de Madrid \\ Departamento de Didáctica de la Lengua y de la Literatura \\ bregueiro@filol.ucm.es
}

[recibido 31/10/2014, aceptado 26/01/2015]

\section{RESUMO}

Tras facer unha revisión do que dixo a crítica verbo da identidade e a configuración do Grupo Bilbao, este artigo ofrece unha nova proposta a partir das novas teorías sobre transculturalidade e identidade híbrida. Deste xeito, proponse a aplicación destas teorías para atopar o nexo de unión dos escritores do Grupo Bilbao nunha identidade híbrida de elementos culturais galegos e madrileños.

PALABRAS CHAVE: Grupo Bilbao, madrigalegos, hibridación, transculturalidade, identidade.

\section{RESUMEN}

Tras una revisión de lo que ha dicho la crítica en relación a la identidad y a la configuración del Grupo Bilbao, el presente artículo ofrece una nueva propuesta a partir de las nuevas teorías sobre transculturalidad e identidad híbrida. Así, se propone la aplicación de estas teorías para encontrar el nexo de unión de los escritores del Grupo Bilbao en una identidad híbrida de elementos culturales gallegos y madrileños.

PALABRAS CLAVE: Grupo Bilbao, madrigalegos, hibridación, transculturalidad, identidad.

\section{ABSTRACT}

After reviewing what critics have already said about the identity and the configuration of the Bilbao Group, this article offers a new proposal taking into account the new theories on transculturality and hybrid identities. Thus, the article proposes to apply these theories to find a link among the writers belonging to the Bilbao Group in a hybrid identity formed by Galician and Madrilenian cultural elements.

KEY wORDS: Bilbao Group, madrigalegos, hybridization, transculturalism, identity.

Regueiro Salgado, B. (2015): "O Grupo Bilbao como modelo de transculturalidade e identidade híbrida", Madrygal (Madr.), 18, Núm. Especial: 431-440.

SUMARIO: 1. Introdución. 2. Que é o Grupo Bilbao de poesía de expresión galega en Madrid? 3. Os Poetas. 4. Achegas previas á identidade do Grupo. 5. Un novo concepto de identidade cultural: o Grupo Bilbao como modelo de transculturalidade e hibridación. 6. Conclusións. 7. Referencias bibliográficas. 


\section{INTRODUCIÓN}

Para facer camiño, temos que empezar polo primeiro paso. Xa non é doado escribir verbo dun tema pouco estudado, o mesmo que non o é traballar sobre autores vivos; pero, cando non é só un autor senón que son varios autores vivos e, ademais de non se ter traballado de abondo, o tema comeza ser obxecto de investigación e de debates, aínda require máis bravura abordalo. De todos os xeitos, os debates, as discrepancias de hoxe e as distintas propostas serán as que permitan que o día de mañá o Grupo Bilbao de poesía de expresión galega en Madrid teña o recoñecemento que merece.

\section{QUE É O GRUPO BILBAO DE POE- SÍA DE EXPRESIÓN GALEGA EN MA- DRID?}

Desde a súa creación en novembro de 1996, todas as antoloxías e estudos (poucos) sobre o Grupo Bilbao redundan na súa xénese e na súa razón de ser. Con todo, cómpre lembrarmos que a idea do Grupo xorde na presentación do libro $O$ gato branco de Vicente Araguas, en xaneiro de 1996, nunha conversa entre Vicente Araguas, Xavier Frías e Fermín Bouza. Resultado daquel encontro son os faladoiros ou tertulias o primeiro sábado de cada mes no Café Comercial, que comezan o 10 de novembro daquel ano coa presenza dos tres fundadores, e que duran até hoxe. Porén, como apunta Frías (2014), se ben é certo que existe vínculo entre o faladoiro e o Grupo poético, non podemos dicir que sexan a mesma cousa, pois o faladoiro acolle a todos os que estean interesados na cultura galega, mentres que o Grupo Bilbao está composto, sobre todo, por poetas que usan o galego como lingua de expresión.

As actividades do Grupo adoitan estar relacionadas co mundo editorial, así como con homenaxes a figuras senlleiras da cultura galega en Madrid. Luis Luna, na súa tese de doutoramento (2013), fala dos anos que van entre 1998 e 2002 como os anos de máximo esplendor do grupo, con publicacións como
Comercial (1998) e En tránsito (2001), e a creación de coleccións como os Cadernos $O$ Roibén, alén dos actos no Ateneo, o Círculo de Bellas Artes, a Universidade Complutense, a librería de Sargadelos, baixo a doce influencia de Inés Canosa, e a Casa de Galicia. Luna considera o ano 2002 como o comezo do declive, pero aínda tiña que vir outro momento dourado: a segunda época do Grupo, iniciada, segundo Frías (2014), en 2008. O estudoso establece como novidades desta etapa a incorporación da UNED aos actos de promoción e á celebración do Día das Letras, os novos libros colectivos do grupo (que deseguido nomearei) e a creación da editorial Lastura, ademais da incorporación de novos autores ao grupo, como veremos máis adiante, e o renacemento de O Roibén en 2012 tras moitos anos de silencio. Se os anos 1998-2002 foron os de máximo esplendor da primeira etapa, coido que os anos dourados da segunda comezan en 2010, ano a partir do cal proliferan os libros colectivos e as homenaxes. Así, desde entón, o Grupo Bilbao fixo tres das catro homenaxes da súa historia $^{1}$ (a Fariña Jamardo, en 2009, desafortunadamente póstuma; a Mariví Villaverde, en 2010; e a Sabino Torres, en 2014), e publicou seis libros colectivos (dous de microrrelatos e catro de poesía): Marés nos pousos de café (2010), E Madrid foi unha praia de baleas na néboa (2011), Bilbao (2012), Hipnotopía en doses pequenas (2013), Filografías (2013) e Esferografías (2014).

Así pois, parece que o Grupo está máis vivo que nunca, como mostran tamén os Seminarios e Congresos que se veñen facendo acerca del. En calquera caso, e a pesar de ser imprescindible dicir todo isto cando se vai falar del, este non é o tema do meu traballo e xa foi estudado con mestría polo estudoso e testemuña de primeira man, Xavier Frías. O que me interesa aquí é falar da identidade do grupo: é unha identidade nacional? Política? Lingüística? Imos velo amodo, pero para iso fai falta revisar a nómina dos seus autores e algunhas hipóteses que lanzou a crítica sobre a súa identidade.

\footnotetext{
${ }^{1}$ A outra homenaxe foi dedicada a Inés Canosa e tivo lugar no ano 2001.
} 


\section{OS POETAS}

Antes de procurar o vínculo que une tantos poetas, é preciso saber de que autores estamos a falar. Xusto aquí atopamos a primeira dificultade, pois, como afirma Frías, o Grupo Bilbao non ten unha lista formal de membros. Nisto coincide Manuel Pereira que, á pregunta de como definiría o Grupo Bilbao, responde o seguinte:

A pertenza viría dada pola publicación nas coleccións vencelladas ao grupo, nomeadamente, a Colección Roibén. E quen decide isto, porque é o que se encarga, infatigablemente, da actividade editorial, é Xavier Frías. De todos os xeitos, nunca houbo un sistema de entrada ou acceso, nin unha listaxe cos nomes dos compoñentes. Volvendo ao principio, penso que esta é a primeira característica do grupo: que aínda está por definir. (Regueiro Salgado 2014: 259)

"Nomeadamente a Colección Roibén", pero Frías apunta: "en Roibén non están todos os que son e non son todos os que están"2. Segundo o crítico impulsor da actividade editorial do grupo, os compoñentes poden dividirse en tres subgrupos:

- Membros fundadores: Vicente Araguas, Fermín Bouza e Xavier Frías.

- Membros nucleares: Manuel Pereira, Rafa Yáñez, Luis Luna, Verónica Martínez e Viqui Veiguela.

- Membros desde a segunda época: Luz Pichel, Ana Cibeira e Begoña Regueiro.

$\mathrm{Na}$ súa tese de doutaramento, Luis Luna engade, ademais, algúns autores que pasaron polo grupo e marcharon, como Crisanto Veiguela, ou "a sétima"3: Victoria Veiguela, Covadonga D’Lom, Rafael Yáñez, Luis Luna, Susana González e Xosé Galán (Luna 2013: 29); todos eles autores que publican en $O \mathrm{Roi}$ bén e que participaron nos faladoiros.
Por outra banda, se volvemos á resposta de Pereira e revisamos os libros colectivos publicados polo Grupo, imos ver que cabería mencionar tamén a Marga Vázquez, que publica nos dous libros de microrrelatos; a Xurxo Fernández (o Jurjo Novoa), que publica nas obras de 2010 e 2011; a Xosé Miguel Barrera, que publica en Marés nos pousos de café; a Pili Mera, partícipe en E Madrid foi una unha praia de baleas na néboa; a Yolanda López, que se incorpora en Filografias (2013); a Montserrat Villar, a última voz unida a Esferografias (2014); e, por suposto, a Claudio Pato e José Manuel Outeiro, que forman parte do primeiro libro colectivo, Comercial (1998).

Aínda que este repaso constate a idea coa que comezamos da falta dun número establecido de poetas, dános unha idea clara para empezar a traballar. Porén, de máis interese para o tema que nos ocupa é a segunda clasificación que fan Luis Luna (2013) e Xavier Frías (2014) respecto da procedencia dos autores. Se comezamos por Frías (2014) vemos que o crítico divide os autores nos seguintes grupos:

- Nacidos en Galicia e emigrados a Madrid, onde el inclúe a Vicente Araguas e Manuel Pereira, e onde tamén estarían Fermín Bouza, Rafa Yáñez, Ana Cibeira e Luz Pichel entre os autores que el recolle, xunto a Marga Vázquez, Xurxo Fernández, Xosé Miguel Barrera, Pili Mera, Montserrat Villar e Yolanda López, que non menciona.

- Fillos de galegos: neste grupo o autor inclúe a Ana Cibeira e engade a etiqueta "que viviron ou non en Galicia". Desde o meu punto de vista, aínda que Ana Cibeira nacera en Caracas, a súa crianza en Santiago de Compostela sitúala máis preto dos autores do primeiro grupo, polo que aquí considero que sería mellor incluír tan só os emigrantes de segunda xeración, é dicir, os fillos de emigrantes galegos que xa naceron e viviron de sempre en Madrid. Neste grupo, entón, estarían Xosé Galán e Begoña Regueiro.

\footnotetext{
${ }^{2}$ En entrevista persoal co autor.

${ }^{3}$ Como chamou Juan Ribera e califica Ana Acuña aos autores que chegaron ao Grupo por mediación das clases de galego que Camen Mejía e mais ela impartían na Facultade de Filoloxía. O nome viría dado pola localización do departamento de Filoloxía Románica naquel tempo (Luna 2013: 29).
} 
- Fillos de galego-falantes de fóra de Galicia, ou, para ser máis precisos, eonaviegos, como os clasifica Luis Luna (2013: 51 et sic.), é dicir, autores da comarca Eo-Navia asturiana que adoptaron o galego como lingua de expresión. Neste caso, atópanse o mesmo Xavier Frías (nado en Salamanca, pero fillo de nai eonaviega) e Victoria Veiguela, nada en León, pero orixinaria e residente da Veiga.

- Alógrafos: este grupo é analizado minuciosamente por Luis Luna (2013: 114 et sic.) e refírese aos que, sen teren vinculación ningunha con Galicia ou co galego, deciden expresarse creativamente nesta lingua. Acertadamente, Luna vincula este feito coas clases de galego de Carmen Mejía e de Ana Acuña, que animaban os seus estudantes a escribiren en galego, alén da boa acollida que lles deu o Grupo Bilbao. Porén, Luna tamén lembra certas críticas en recitais e actos, dedicadas aos poetas que escribían en galego sen teren relacións con Galicia. Este é motivo, segundo o crítico, de que moitos deles, ou mellor dito, todos eles, agás Luis Luna, deixaran de escribir en galego e se desvinculasen do grupo axiña. Os alógrafos serían aqueles que xa denominamos como "A sétima”, é dicir, Óscar Curieses, Luis Luna, Susana González e Covadonga D’Lom.

- Non alógrafo, pero tamén de esta "sétima", como sinala Frías (2010: 76), é Xosé Galán que, se ben si tiña vinculación con Galicia, non usaba o galego como lingua de expresión; no caso de Begoña Regueiro, sendo alumna de Ana Acuña e Carmen Mejía no ano 2000, non comezou escribir en galego até que os estudos de doutoramento a puxeron en contacto con Manuel Pereira, no ano 2005.

A variedade das orixes dos autores deixa claro que a identidade común do grupo non é o lugar de nacemento nin a procedencia. $\mathrm{Pa}-$ saremos agora a revisar o que a crítica di ao respecto, pero, antes, é preciso tamén lembrar, xunto con Frías, a importancia do bilingüismo no Grupo, pois se consideramos só os autores que aparecen na listaxe de Frías, veremos que todos eles publicaron tamén en castelán, ou, como mínimo, en edición bilingüe, como é o caso de Manuel Pereira. Isto lévanos de novo ao tema da identidade. O mesmo Frías (2014) di que a identidade galega non é o elemento característico do grupo senón a lingua, que sería, así, o elemento aglutinante. Non hai dúbida posible de que o emprego da lingua dá unidade ao grupo, pero, non hai nada máis? Entón, por que marcharon aqueles que, de feito, non tiñan ligazón ningunha con Galicia máis aló da lingua (coa única excepción de Luis Luna)? Quizais é preciso repensar o que significa identidade hoxe. Iso é o que me propoño facer neste artigo.

\section{ACHEGAS PREVIAS Á IDENTIDA- DE DO GRUPO}

Como xa dixen, a pesar de haber poucos estudos sobre o grupo, a súa identidade común é un dos temas que sempre están enriba da mesa cando se fala del. Que dá unidade ao grupo se os poetas son de distintas xeracións e fan distintos tipos de poesía?

A primeira que trata de definilo é Carmen Mejía cando, en 1998, lle encargan o prólogo do que será o primeiro libro colectivo do grupo. A profesora comeza dicindo que son "poetas que desde Madrid escriben en lingua galega" (Mejía 1998: 3), polo que parece que a unión se establece en torno á lingua, pero, máis adiante, afirma: "as xentes galegas non deixan o seu "enxebrismo", neste caso a súa lingua, a súa cultura, aínda que vivan en Madrid" (Mejía 1998: 3). Porén, deixamos visto que non todos os membros do Grupo Bilbao son "xentes galegas", polo que parece que esta primeira achega (que como eu hoxe, se atreve con algo aínda por definir) non acha de todo a identidade do Grupo.

A seguinte aproximación é a que fan Ana Acuña, no prólogo, e Borobó, no epílogo, do libro colectivo En tránsito (2001). Aquí, de novo, a confusión vén de asimilar o Grupo Bilbao á "nacionalidade" galega e, aínda máis, á emigración de galegos en Madrid. Faise coa intención de unir a este autores cos outros emigrados que estiveron "en tránsito" por Madrid, como a mesma Rosalía. Esto sería válido para moitos dos poetas máis senlleiros do Grupo, como Araguas, Pereira, Pichel... pero deixaría fóra a moitos outros, como Luis Luna, Viqui Veiguela ou o mesmo Xavier Frías, sen contar todos os da "Sétima". No epílogo Borobó emprega o mesmo criterio 
e fala de poetas nos que "os pés pisarán chan madrileño, pero o seu pensamento voa ata o chan nativo" (2001: 218). A diferenza está en que Borobó fala de madrigalegos en xeral, non do Grupo Bilbao, polo que cabería entender que o que pasa é que non todos os membros do Grupo Bilbao son madrigalegos; só algúns deles o son, os que caberían tamén na clasificación de Ana Acuña.

No prólogo de Bilbao, en 2012, Luis Luna, como alógrafo e membro do grupo, xa define os participantes deste como "creadores que se expresan en lingua galega e moran ou están de paso por Madrid" (2012: 6). Con esta definición parece que nos achegamos máis ao Grupo Bilbao a día de hoxe ou, polo menos, deixan de ser excluídos todos os galegofalantes ou galegoescribintes non nacidos en Galicia, os descendentes de emigrantes e os alógrafos. Porén, parece que ten que haber algo máis que a lingua ou, dito doutro xeito, parece que a lingua compartida debe ser a parte visible de algo máis profundo... a identidade? Quizais sería a razón de que os que só compartiron a lingua tivesen unha presenza máis anecdótica no grupo, máis como unha experimentación creativa que como unha verdadeira pertenza. Luna explica a transitoriedade destes poetas por razóns contextuais relacionadas cunhas circunstancias socioliterarias concretas, pero el mesmo fala tamén do "experimento alógrafo" (Luna 2013: 118), o que me leva a pensar, de novo, que máis alá de experimentos, o vínculo do Grupo ten que ser máis profundo.

Anos despois do prólogo de En tránsito, Ana Acuña no seu libro Facer literatura galega en Madrid (1950-2000) (2009), retoma o tema e fala do Grupo Bilbao como un grupo de resistencia. A estudosa afirma que "neses espazos galegos en Madrid vaise reivindicar e recoñecer a identidade galega en maior ou menor medida" (2009: 30), idea que recolle Luna para engadir que o Grupo "surge como necesidad de estimular la creación gallega y de asociarse para resistir el ninguneo, la marginación y la postergación de los autores que residen en Madrid por parte del canon o los grupos ortodoxos" (Luna 2013: 17). Certo, pero a que grupos ortodoxos nos estamos a referir? Os da Galicia interior que ignoran o Grupo ou non lle prestan atención? Os escritores non galegofalantes e orixinarios doutras partes residentes en Madrid? O canon de literatura en español? Os galegos que moran en Madrid e non poñen atención nos escritores galegos que viven na capital? Resistencia fronte a que?

Acuña tamén recolle outras características que aparecerían no grupo, como a defensa do idioma e a cultura galega, o oficio literario ou o activismo cultural, a amizade, a recuperación de figuras senlleiras e a conciencia do seu papel na permanencia da cultura galega en Madrid (Acuña 2009: 470-473). Como afirma Luis Luna (2013:17), todo isto non inclúe a militancia política, idea na que tamén insiste Frías (2014).

Visto todo isto, parece que o que queda claro é que o elemento aglutinador, como Frías e Luna din, é a lingua, e trátase dunha lingua nun contexto específico que Luna califica como exotopía e Frías analiza como literatura de fronteira que precisa da aparición do grupo como apoio para manter a lingua B no contexto da lingua A. Ambos conceptos parecen adecuados á situación, pero de novo, parece que se cinguen só á lingua e que aceptan conceptos como "fronteira" ou "nación" e dan por sentada a existencia de dúas linguas ou dúas culturas en pugna. E, se damos a volta e, en lugar de falarmos de loita, falamos de hibridación?

\section{UN NOVO CONCEPTO DE IDENTI- DADE CULTURAL: O GRUPO BILBAO COMO MODELO DE TRANSCULTU- RALIDADE E HIBRIDACIÓN}

Tras a revisión de todo o que se dixo até agora, o que me propoño é lanzar unha nova proposta ou hipótese a partir de novos postulados teóricos que fan unha reinterpretación da identidade tras pasar por riba de conceptos como nación, tal como se define nos dicionarios da Real Academia Española e da Real Academia Galega; é dicir, asumindo que se trata dunha comunidade de habitantes que comparte un territorio, unha lingua, unha orixe étnica, unha cultura e uns intereses económicos, pero que, como especifica a RAG, pode 
estar organizada como Estado ou non. Fronte a estas definicións, varios estudos demostraron a falta de correspondencia entre os límites de nación-territorio-lingua e, especialmente, como salienta Lambert (2006: 120), a falta de correspondencia entre os mapas lingüísticos e os mapas políticos. Aceptar isto implica dar un primeiro paso para resolver os problemas que esta falta de coincidencia implica, posto que, como tamén indica Lambert: "Allí donde las fronteras políticas y lingüísticas no coinciden -y nunca coinciden-, el principio de las literaturas nacionales no funciona" e "lo que no puede ser representado por este paradigma ha sido olvidado, o excluido, o marginalizado" (2006: 120). Será por isto que, desde a Galicia institucional interior que recoñece a "literatura galega", non se preste atención a unha literatura en galego que se escapa das que considera as súas fronteiras? Quizais, entón, ao resolver este problema poderiamos contribuír ao recoñecemento para o Grupo na medida que o merece.

De calquera maneira, antes de formular a miña hipótese faise necesario repasar brevemente algúns conceptos teóricos novos ou a reinterpretación feita pola crítica contemporánea dalgúns conceptos do século dezanove.

O primeiro que cómpre revisar e a definición de identidade. Nalgúns dos seus traballos, Randoph D. Pope recolle a cita de Maalouf segundo a cal, a identidade "se consideraría (...) como la suma de todas nuestras lealtades" (Pope 2006: 345); de aquí deducimos a posibilidade dunha identidade múltipla ou híbrida. Así mesmo, sinala que é nas cidades "donde la vida se vive en la riqueza de todas sus lealtades" (Pope 2003: 346). Entón, que lugar mellor que Madrid para desenvolver unha identidade múltipla?

Outro concepto que temos que ter en conta é o de hibridación. Neste caso é Neverdeen Pietersen o que dá a chave do termo ao falar de "los que se sientan a horcajadas o se sitúan entre categorías y combinación de identidades" (Pietersen 2008: 67). O crítico pon o exemplo do censo dos Estados Unidos do ano 2000 no que, por vez primeira, era posible escoller unha identificación múltipla e ser, ao mesmo tempo, caucásico e hispánico, etc. No noso caso, pódese ser á vez galego e madrileño? Centrándonos no Grupo Bilbao, é moi posible que non todos os membros do Grupo teñan a mesma conciencia de identidade híbrida porque, retomando a Pope, non terán as mesmas lealdades. É lóxico pensar que Xosé Galán ou Begoña Regueiro teñan unha maior hibridación que Manuel Pereira ou Vicente Araguas polo feito de naceren e desenvolveren toda a súa vida en Madrid e, de feito, para Pietersen o exemplo obvio de autoidentificación híbrida é a segunda xeración de emigrantes, dos que di que teñen "identidades con guion" (2008: 81). Porén, cando Manuel Pereira é preguntado como é ser "madrigalego", o poeta de Ouzande responde:

Verbo de ser madrygalego, é desfrutar á vez de ser galego, con todo o que significa pertencer á cultura galega, e ser un madrileño adoptivo en moitas cousas. Familiarmente, a miña muller é de Madrid, de Madrid Madrid, e a miña identidade consorte é tamén ser madrileño. Teño a sorte de pertencer a eses dous mundos, o de Galicia e o de Madrid, tendo en conta que, ademais, hai grandes personaxes galegos que conformaron a cultura madrileña. (Regueiro Salgado 2014: 259)

É especialmente interesante subliñar aquí as diferentes identidades das que fala o autor en apenas seis liñas. Pereira fala de pertenza á cultura galega, é dicir, dunha identidade cultural galega, e dunha adopción madrileña, ou sexa, o que poderiamos chamar unha identidade cotiá madrileña. En calquera caso, é máis claro cando o mesmo autor fala dunha identidade consorte que é súa tamén dalgún xeito. "Teño a sorte de pertencer a eses dous mundos": e que é iso senón, polo menos até certo punto, unha identidade híbrida? Paga a pena salientar unha cousa máis das verbas de Pereira. O autor fala de "personaxes galegos que conformaron a cultura madrileña", onde queda claro que a hibridación non vai só nunha dirección senón nas dúas. $\mathrm{O}$ individuo desenvolve unha identidade complexa onde as lealdades, por empregar os termos de Maalouf, se multiplican (que non se dividen); pero tamén a sociedade é híbrida (ou transcultural, como veremos decontado), porque se vai formando coas identidades culturais 
dos individuos que a conforman. Madrid non tería a mesma identidade cultural sen as achegas de todos os seus habitantes, entre eles, neste caso, os poetas do Grupo Bilbao, cunha identidade cultural galega.

De volta o termo "hibrización", hai dous aspectos máis apuntados polo crítico que deberiamos ter en conta. En primeiro lugar, de xeito similar ao que vimos antes en relación ás dificultades en canto ao recoñecemento que implica a non concordancia entre fronteiras lingüísticas e fronteiras políticas, Pietersen apunta á ignorancia na que moitas veces quedan as identidades híbridas: "son los híbridos los que no se tienen en cuenta, los que no se acomodan" (2008: 68). Terá algo que ver coa pouca atención prestada ao Grupo Bilbao desde a Galicia interior?

Por outra banda, Pietersen fala dos "híbridos" como mediadores, no mellor dos casos:

En los estudios culturales, la hibridación implica un amplio registro de identidades múltiples, entrecruzamientos, mezcla, experiencias y formas de creciente migración y vidas diaspóricas, de comunicación intercultural intensiva, de multiculturalismo cotidiano y erosión de barreras. En los brotes optimistas sobre la hibridación, los híbridos se concebían como lubricantes en las luchas de la cultura: eran los negociadores que asegurarían un futuro libre de xenofobia. (2008: 70)

No caso que nos ocupa, o termo xenofobia parece que queda un pouco grande, pero, agás dela, a idea parece concordar coa que apunta Frías cando di que o Grupo Bilbao serve de ponte entre as literaturas en galego e en castelán. Até que punto o optimismo é realista neste caso, non podemos sabelo, pero dalgún xeito as pontes están alí, como apunta tamén Pereira na súa entrevista:

Dos que somos clásicos do grupo Bilbao, nin Vicente, nin Fermín, nin Rafa, ni Xavier Frías, somos persoas que teñamos aversión a Madrid. Somos persoas que nos atopamos ben nesta cidade. Que iso poida dar unha visión mellor en Galicia... non o sei; como alí a repercusión é pequena, pois tamén será pequena respecto desta visión, digamos, non despectiva de Madrid. (2014: 260)
Parece claro: a función das pontes tamén depende da súa visibildade...

O último concepto que temos que revisar é o de transculturalidade, empregado por Wolfang Welsch como novo concepto de cultura que se adapta ás culturas contemporáneas, tan afastadas xa do concepto tradicional de cultura, establecido no século XVIII por Samuel von Pufendorf e, pouco despois, apuntalado e matizado por Herder. Segundo o filósofo alemán, a cultura debe determinar a vida toda do pobo, desde o máis global até o máis particular; está unida ao pobo e é cultura dun só pobo fronte a todos os demais. O problema xa non é o simplismo no que cae a definición, senón que, segundo esta, as culturas son, empregando a metáfora de Welsch, como bólas pechadas ou illas autónomas nas que coincide a expansión lingüística e territorial dun pobo, idea utópica e irreal, como xa vimos.

O obsoleto do termo posibilita, entón, que o crítico faga unha nova reflexión sobre a cultura e chegue ao concepto de transculturalidade como o máis adecuado para o mundo moderno (máis aló da multiculturalidade ou a interculturalidade, nas que, de feito, segue a existir o recoñecemento de fronteiras e de outredade). A transculturalidade é definida por Welsch en función de cinco aspectos que se refiren a un macronivel (a sociedade) e a un micronivel (o individuo). No macronivel, o crítico fala de imbricación externa das culturas, que presentan formas de vida moi semellantes; do carácter híbrido das sociedades e da disolución da diferenza entre o alleo e o propio. Isto vén constatar o que diciamos antes verbo da cita de Pereira; pero máis esclarecedor para nós é o que di respecto do micronivel, onde fala do carácter transcultural dos individuos e do desacoplamento da identidade cultural e nacional.

No que atinxe á transculturalidade dos individuos, vén sendo o mesmo que xa vimos respecto da hibridación, é dicir, trátase dunha formación cultural determinada por varias procedencias e relacións culturais.

Máis novidoso, por tanto, é o que ten que ver co desacoplamento entre a identidade cultural e a identidade nacional. Con isto, Welsch refírese a que a formación cultural dun 
individuo non ten que ser determinada só pola súa patria, nacionalidade ou pertenza a un Estado concreto, senón que a formación cultural pode ser ampla e plural e as fontes poden ser diversas, sobre todo nos Estados nos que a liberdade de acceso á información é unha lei básica. Ineludiblemente, isto lévanos aos alógrafos dos que falamos antes, formados na lingua e na cultura galega nas aulas de Ana Acuña e Carmen Mejía na Universidade Complutense de Madrid. Estes autores, con independencia da súa orixe, foron formados nunha identidade cultural galega e decidiron acollela, na súa tradición literaria e na súa lingua, polo menos por un tempo. Afirma Welsch que "los individuos pueden decidir cada vez más su pertenencia", pero: "hay que decidirse por ella de forma consciente (...) y posteriormente hay que haberla elegido y afirmado como tal. Solo en esta casi "patria" no es una categoría natural sino cultural y humana" (Welsch 2008: 130). Así pois, os alógrafos decidiron asumir esta identidade cultural galega por un tempo, pero, despois, a maior parte deles non a afirmaron como tal.

Retornando ao concepto de transculturalidade, cómpre sinalar tamén que non implica a homoxeneización cultural, senón que, pola contra, favorece a aparición dunha nova diversidade de grupos en formacións transculturais:

Diferentes grupos o individuos recurren en la selección de sus elementos de identidad a diferentes fuentes culturales. Entonces, resulta diferente el inventario de las nuevas redes de identidad; y puesto que además los mismos elementos, si se combinan de diversas formas, producen diferentes estructuras, se puede esperar en general una diferencia considerable de estos modelos de identidad transcultural. (Welsch 2008: 128)

Así pois, se combinamos a identidade cultural galega coa vida cotiá madrileña obteremos a identidade transcultural madrigalega ou, para sermos máis precisos, a identidade transcultural dos escritores do Grupo Bilbao. As doses serán distintas e a orixe rexional diversa tamén poderá matizar o sabor final, pero o que todos comparte, veñan de onde veñan, é esa mesturanza.

\section{CONCLUSIÓNS}

Á luz destes novos conceptos, coido que é posible lanzar unha nova hipótese sobre a identidade híbrida e transcultural do Grupo Bilbao que, como vimos de sinalar, explicaría, ademais, moitas das súas características e das pecularidades dos seus poetas.

Poderiamos falar entón do Grupo Bilbao como un espazo de resistencia, pero non só como baluarte da cultura e da lingua galega en Madrid, senón tamén dunha identidade transcultural froito da hibridación dunha identidade cultural galega, adquirida non só por nacemento senón tamén por formación, e unha localización xeográfica en Madrid con todo o que as prácticas, costumes e hábitos se refire; ou sexa, o que quizais poderiamos chamar unha cultura da "cotidianidade" (tan preto da definición de cultura de Herder). A defensa desta identidade estaría a desafiar lindeiros políticos e fronteiras, e tendendo pontes, como ben di Xavier Frías.

Así, en primeiro lugar, o grupo convértese nun espazo onde se coida e se mima a identidade cultural galega con agarimo e pulcritude. Por outro, érguese fronte á crítica da Galiza interior que non ten en conta o que se fai fóra das súas fronteiras políticas (que non lingüísticas) e que só atende á literatura en Galicia, non en galego e, por suposto, non galega (empregando os termos de Lambert 2006: 12).

Se, de acordo con Dolores Romero (2006), a configuración dunha nación e a creación dunha literatura son procesos simultáneos, talvez a configuración dunha identidade transcultural ou, mellor dito, o recoñecemento de que as sociedades son transculturais e de que o concepto de cultura do século dezanove non é válido nun mundo global no que os movementos migratorios son constantes, tamén precisa da creación dunha literatura nova.

Unha das manifestacións desa literatura é a do Grupo Bilbao, que non só plasma a transculturalidade na súa temática ou nas súas edicións bilingües, senón que, ademais, chama pola globalidade e o diálogo entre culturas por medio das traducións e edicións plurilingües ás que nos ten acostumados Xavier Frías ${ }^{4}$. 
Como dicía ao principio, é difícil estudar o que aínda está vivo, máis aínda cando se trata dun fenómeno que non queda claro de todo para a crítica e, aínda máis, se unha forma parte diso. Porén, como tamén dixen, o camiño se fai andando, e para que os estudosos do futuro teñan algo para comezar as súas investigacións desde a distancia e a obxectividade precisas, é necesario que hoxe fagamos estas pequenas achegas. Vai aquí a miña desde a plena conciencia de que é só unha proposta máis que talvez prenda no percurso doutros investigadores.

\section{REFERENCIAS BIBLIOGRÁFICAS}

Acuña Trabazo, Ana (2009): Facer literatura galega en Madrid (1950-2000). Santiago de Compostela: Universidade.

(2012): “Os primeiros anos do grupo Bilbao (1996-2001)”, Revista de lenguas y literaturas catalana, gallega y vasca 17, pp. 261-272.

(2014): Conciencia política e literatura galega en Madrid (1950-2000). Vigo: Xerais.

FríAs Conde, Xavier (ed.) (2010a): Marés nos pousos de café. Mostra de poetas de expresión galega en Madrid. Pontevedra: El Taller del Poeta S.L.

(2010b): Café de Saudades. Madrid: Amargord Ediciones.

(2015): “Crônica do Grupo Bilbao 1996-2014: uma visão desde dentro”, en C. Mejía Ruiz e X. Frias Conde (coords.), R. Pichel Gotérrez e J. Rivero Grandoso (eds.), Identidade, alteridade e exilio na literatura galega (Núm. Especial 18 de Madrygal. Revista de Estudios Gallegos). Madrid: Universidad Complutense, Servicio de Publicaciones, pp. 421-429.

Frías Conde, Xavier e Luis Luna (eds.) (2012): Bilbao. Madrid: Amargord Ediciones.

LAMBerT, José (2006): “En busca de los mapas literarios del mundo”, en D. Romero López (ed.), Naciones literarias. Madrid: Anthropos, pp. 113-128.

Llamas Ubieto, Miriam, Amelia Sanz Cabrerizo e Begoña Regueiro Salgado (2014): “A Global Memory for e-Literatures? Modifying the Patterns of Production”, ICLA (no prelo).

LunA, Luis (2013): La colección O Roibén, órgano de expresión de la poesía gallega en Madrid del cambio de siglo. Tese de doutoramento inédita. Madrid: Universidad Nacional de Educación a Distancia.

MaIner, José Carlos (2006): “La invención de la literatura española”, en D. Romero López (ed.), Naciones literarias. Madrid: Anthropos, pp. 201-230.

NeVerdeen Pietersen, Jan (2008): "La hibridación ¿y qué? La reacción de la antihibridación y los enigmas del reconocimiento", en A. Sanz Cabrerizo (ed.), Interculturas, transliteraturas. Madrid: Arco/Libros, pp. 67-105.

Pope, Randoph D. (2003): "Resisting the Global: The Importance of the National for a Comparative History of Iberian Literatures", Neohelicon XXX/2, pp. 79-84.

\footnotetext{
${ }^{4}$ As traducións son un dos signos de intencionalidade global, segundo o estudo de Llamas Ubieto, Sanz Cabrerizo e Regueiro Salgado (2014).
} 
(2006): "Contra la globalización: la importancia de lo nacional para una historia de la literatura comparada de las literaturas ibéricas", en D. Romero López (ed.), Naciones literarias. Madrid: Anthropos, pp. 341-352.

Regueiro SAlgado, Begoña (2014): "Descafeinado de máquina e conversas. Entrevista a Manuel Pereira Valcárcel”, Madrygal. Revista de Estudios Gallegos 17, pp. 255-260.

Romero LóPEz, Dolores (ed.) (2006): Naciones literarias. Madrid: Anthropos.

SANZ CABrerizo, Amelia (ed.) (2008): Interculturas, transliteraturas. Madrid: Arco/Libros.

VV.AA. (1998): Comercial. Poesía galega en Madrid. A Coruña: Ediciós Río Xuvia, Colección O Roibén.

VV.AA. (2001): En tránsito. Poesía galega en Madrid. Sada: Ediciós do Castro.

VV.AA. (2010): Muller de doce sal. Homenaxa a Inés Canosa. Madrid: vtp editorial.

VV.AA. (2011): E Madrid foi unha praia de baleas entre néboas. Asturias: La Fábrica de Libros.

VV.AA. (2013): Filografias. Toledo: Lastura.

VV.AA. (2013): Hipnotopía en doses pequeñas. Toledo: Lastura.

VV.AA. (2014): Esferografias. Toledo: Lastura.

WELSCH, Wolfgang (2008): "El camino hacia la sociedad transcultural", en Interculturas, transliteraturas. Madrid: Arco/Libros, pp. 107-132. 